\title{
Oral and Dental Complications of Radiotherapy for Head and Neck Cancer: Knowledge of Dental Practitioners in Saudi Arabia
}

\author{
Ahmed Shaher Alqahtani*, Yousef Alshamrani, Yaser Alhazmi, Esam Halboub
}

\begin{abstract}
Objectives: Toxicities of the oral soft and hard tissues due to the radiotherapy of the head and neck cancer can potentially lead to interruptions of cancer treatment and/or dose reduction, resulting in poorer outcomes. The aim of this study was to assess the knowledge of dental practitioners in Saudi Arabia about oral and dental assessment for and complications of radiotherapy of head and neck cancer. Materials and Methods: An online, already validated, self-administered questionnaire was sent via an online link through WhatsApp groups and other Social Media platforms to reach out to the majority of targeted samples (dental practitioners working in Saudi Arabia). Responses were statistically described and analyzed based on the different grouping factors: gender, specialty, working sector, region of work and experience. Results: There were 370 respondents, 257 (69.5\%) of them were males. Most of the respondents were general dental practitioners [144 (38.9\%)], The percentages of the correct answers range from as low as 26.2 to as high as $97 \%$. The per cent of correct answers by the respondents in 18 out of 31 questions was above $75 \%$. Females, dental specialists (specifically prosthodontics), working in public sectors and in the central and western regions of Saudi Arabia were associated with higher levels of knowledge. Conclusion: Our results show highly variable knowledge of dental practitioners on oral and dental assessment for, and complications and management of radiotherapy to the head and neck area; that knowledge seems to fluctuate considerably with gender, experience, work sector and specialty.
\end{abstract}

Keywords: Head and neck cancer- radiotherapy- knowledge- complication- dentists- oral and dental assessment

Asian Pac J Cancer Prev, 22 (7), 2033-2041

\section{Introduction}

Head and neck cancer (HNC) is an umbrella term refers to a group of cancers developing in the oral cavity, pharynx, larynx, paranasal sinuses, nasal cavity, salivary glands, or lymph nodes of the head and neck; it is considered the ninth most common cancer worldwide (Amin et al., 2017). Oral cancer accounts for about 26\% among all the head and neck cancers recorded annually in the Kingdom of Saudi Arabia (KSA), and greater number of them is detected at advanced stage. Oral cancer in KSA is strongly linked to the frequent use of smokeless tobacco (Shammah) (Quadri et al., 2019; Patil et al., 2019) and to the chewing of qat (Quadri et al., 2015), an evergreen shrub chewed for it's an amphetamine-like effects (Al-Hebshi and Skaug, 2005). A large number of oral cancer cases are documented from the southwestern region of KSA especially in Jazan province and are invariably related to the consumption of Shammah(Quadri et al., 2019; Patil et al., 2019; Quadri et al., 2015).

Surgery, radiotherapy, or chemotherapy are commonly employed, either individually or in combination, for treatment of HNC. Radiotherapy to oropharyngeal region may induce squamous epithelium destruction, inhibit proliferation of transit cells, and absence of cell regeneration leads to acute mucositis. Also, high-dose radiation to tooth-supporting bone results in hypoxia and reduces the vascular supply to the bone and soft tissues, causing fibrosis and vascular thromboses (Shih et al., 2003). Given the treatment-related toxicities to the soft and hard tissues of the oral region, cancer treatment might be interrupted, or dose might be reduced, resulting in poorer outcomes such as increased morbidity and possibly decreased survival (Jasmer et al., 2020).

Oral and dental complications include mucositis, infections, pain, salivary gland dysfunction, taste change, dysphagia, trismus, and soft and hard tissue necrosis (Martinez et al., 2020; Bonar-Alvarez et al., 2020; Brook, 2020). Therefore, dental assessment and management of HNC patient pre and post cancer treatment is one of the cornerstones in the comprehensive care approach (Bacher et al., 2020; Colloc et al., 2020; Moore et al., 2020). The main aim of doing so is to eliminate or at least reduce 
Ahmed Alqahtani et al

the risk of the above mentioned complications. Thus, it is essential that all health professionals including dentists need to be aware of and knowledgeable about the prevention, diagnosis, and management of oral complications of radiotherapy in order to ultimately minimize the impact of these complications on the patient's life (Cho and Kumar, 2019; McCaul, 2012). In this context, a few studies have assessed this issue and revealed variable knowledge among dental practitioners/ students (Suhaimi, 2017; Dewan et al., 2014; Mainali et al., 2011; Guneri et al., 2008). No single study has been conducted to investigate the knowledge and awareness among dentists in Saudi Arabia towards oral and dental assessment and management of head and neck cancer patients pre and post-radiotherapy, and hence this study sought to do so.

\section{Materials and Methods}

\section{Methodology}

This study is of cross-sectional, questionnairebased study design. The population framework was dental practitioners working currently in Saudi Arabia. The questionnaire's items were taken from previously validated questionnaires used in the same context (Mainali et al., 2011; Guneri et al., 2008). For more confirmation, the questionnaire was administered to three experts in oral medicine and pathology, who had a clear understanding of the pre and post radiotherapy oral complications and proper managements. Their feedbacks were minor, and the questionnaire was corrected accordingly. Then, the questionnaire was administered to 18 dentists from different dental specialties and asked whether they had difficulty in understanding any questions. Their feedbacks showed that the questionnaire was appropriate and easy to understand; minor corrections were made at this stage.

The questionnaire included 20-questions pertaining to the knowledge on oral/dental assessment for and management of HNC patients pre- and post-radiotherapy. The first 5 items of the questionnaire were about the participants' demographic information (gender, specialty, working field, working experience and region of work in KSA). Of the other 15 items, 7 were directed to the oral/ dental assessment and information prior to radiotherapy. The remaining 8 items are related to oral complications of radiotherapy and their management protocols. The stems and alternatives (answers) of all items are listed in Table 2.

To confirm nationwide distribution, the authors were keen to target as many as possible dental practitioners with different background (general dentists, specialists, consultants, academics) at different working fields (Private clinic, public hospital, health care center and universities) and in the five regions of the KSA (Central, Western, Eastern, Northern and Southern). To do so, the questionnaire was administered to the potential participants using Google form via an online link through WhatsApp groups and other Social Media platforms depending on friends in the different regions of KSA. Furthermore, five reminders were sent through these channels aiming to increase the response rate. Responses to the questionnaire were sensitive to the Internet Protocol
(IP) Address assuring no duplicated responses. The time frame during which the questionnaire was circulated was between $26^{\text {th }}$ May and $18^{\text {th }}$ June 2020.The study protocol was approved in advance and Ethical Clearance was obtained from College of Dentistry, Jazan University. The research was self-funded and there are no conflicts of interest to be reported.

\section{Statistical analysis}

Data were obtained in "excel" format and exported into SPSS program, Version 21 (Armonk, NY: IBM Corp) for further analyses. As all data were qualitative, they were presented as frequencies and corresponding percentages. All variables were described for the whole sample, and analyzed by different grouping factors (gender, specialty, work sector, year of experience, and region of the work) using Chi square/Fisher exact tests as appropriate. For questions with multiple correct/possible choices ("Mark all that apply"), each choice was statistically dealt with as a separate variable with "positive/yes" answer when marked and "negative/no" answer when not marked. A P value of less than 0.05 was considered significant.

\section{Results}

There were 370 respondents, 257 (69.5\%) of them were males. Most of the respondents were general dental practitioners [144 (38.9\%)], followed by oral surgery/ medicine/pathology specialists [57 (15.4\%)], endodontists [34 (9.2\%)], and periodontists [32 (8.6\%)]; the other specialties represented up to $28 \%$. Most of the respondents reported working in universities [234 (63.2\%)], and half of them had less than 5 years of experience [183 (49.5\%)]. More than $63 \%$ of the respondents worked in the central and western region of the kingdom (Table 1).

Table 1. Demographic Data of the Sample

\begin{tabular}{|c|c|c|}
\hline Variable & Categories & $\mathrm{n}(\%)$ \\
\hline \multirow[t]{2}{*}{ Gender } & Males & $257(69.5)$ \\
\hline & Females & $113(30.5)$ \\
\hline \multirow[t]{6}{*}{ Specialty } & General Dentists & $144(38.9)$ \\
\hline & Oral surgery/Medicine/Pathology & $57(15.4)$ \\
\hline & Endodontist & $34(9.2)$ \\
\hline & Periodontist & $32(8.6)$ \\
\hline & Prosthodontist & $16(4.3)$ \\
\hline & Others & $87(23.5)$ \\
\hline \multirow[t]{4}{*}{ Working field } & Health care center & $39(10.5)$ \\
\hline & Private clinic & $18(4.9)$ \\
\hline & Public hospital & 79 (21.4) \\
\hline & University & $234(63.2)$ \\
\hline \multirow{3}{*}{$\begin{array}{l}\text { Working } \\
\text { experience as a } \\
\text { dentist }\end{array}$} & Less than 5 years & $183(49.5)$ \\
\hline & $5-10$ years & $120(32.4)$ \\
\hline & More than 10 Years & $67(18.1)$ \\
\hline \multirow{5}{*}{$\begin{array}{l}\text { Working } \\
\text { Region }\end{array}$} & Eastern & $24(6.4)$ \\
\hline & Western & $63(17)$ \\
\hline & Northern & $48(13)$ \\
\hline & Southern & $120(32.4)$ \\
\hline & Central & $115(31.1)$ \\
\hline
\end{tabular}


Table 2. Responses* of the Whole Sample

Questions
Q6. As a dentist, do you think that there is any necessity
and neck cancer patients?
Q7. The ideal time to do a comprehensive oral evalua-
tion for head and neck cancer patients:
Q8. Before radiotherapy for head and neck cancer
patient, oral/dental assessment and management should
include: "Mark all that apply"

Q9. Which oral problems associated with radiotherapy need to be discussed with head and neck cancer patients before radiotherapy? "Mark all that apply"

Choices
Yes
I don't know
After a cancer diagnosis and before radiotherapy
After finishing radiotherapy
During radiotherapy
Only as needed
Thorough hard and soft tissue examination
Appropriate radiographs such as full mouth x-ray and panorama
Extraction of deeply impacted teeth without pathology
Fluoride application
Extraction of teeth with poor prognosis
Oral Mucositis

$\mathrm{N}(\%)$
$\mathbf{3 5 9}(\mathbf{9 7 )}$
$2(0.5)$
$9(2.4)$
$\mathbf{3 4 2}(\mathbf{9 2 . 4 )}$
$14(3.8)$
$5(1.4)$
$9(2.4)$

344 (93)

295 (79.7)

$115(31.1)$

200 (54.1)

322 (87)

279 (75.4)

Hypersalivation $46(12.4)$

Loss or change of taste sensation $\quad 302(81.6)$

$\begin{array}{ll}\text { Oral candidiasis } & 265(71.6)\end{array}$

Difficulty in mouth opening $\quad 195(52.7)$

Dental caries $\quad 265(71.6)$

$\begin{array}{ll}\text { Osteoradionecrosis } & 323(87.3)\end{array}$

Q10. What should the dentist recommend for head and neck cancer patients before radiotherapy? "Mark all that apply"

Alcohol-free antiseptics

220 (59.5)

304 (82.2)

$53(14.3)$

289 (78.1) surgery such as teeth extraction:

Sugar-containing food and drink

After a week

267 (72.2)

After two weeks

As soon as possible

312 (84.3)

Q12. Is oral prophylaxis (teeth cleaning) recommended Yes

$40(10.8)$

No

296 (80)

Q13. How often head and neck cancer patients need to follow up with a dentist post-radiotherapy?

Every 3-4 months

$53(14.3)$

Q14. How does the dentist usually handle post-radiation oral complications? "Mark all that apply"

Dentist treats by him/herself

319 (86.2)

Refer to a dental specialist

$91(24.6)$

Q15. The oral cavity is often subject to complications from radiotherapy because: "Mark all that apply"

No need for any treatment

Many patients experience hypersalivation

The tissue in the oral cavity thickens

Soft tissues in the mouth become easily damaged and infected

Q16. Which of the following statements about the oral complications of head and neck cancer radiotherapy are correct? "Mark all that apply"

Oral mucositis can increase the risk of oral pain and systemic

Oral complications may lead to lowering the dosages and possibly discontinuing cancer treatment in children 


\begin{tabular}{|c|c|c|}
\hline Questions & Choices & $\mathrm{N}(\%)$ \\
\hline \multirow{4}{*}{$\begin{array}{l}\text { Q17. Dental decay occurs more rapidly after head and } \\
\text { neck radiation treatment because: "mark all that apply" }\end{array}$} & There is a change in the flow rate for saliva & $344(93)$ \\
\hline & There is a change in the composition of saliva & $151(40.8)$ \\
\hline & The ability to taste is impaired & $74(20)$ \\
\hline & Daily self-application of topical fluoride & $28(7.6)$ \\
\hline \multirow{4}{*}{$\begin{array}{l}\text { Q18. For a patient experiencing xerostomia, he/she is } \\
\text { recommended to: "mark all that apply" }\end{array}$} & Sip water & $265(71.6)$ \\
\hline & Chew sugarless gum & $342(87.6)$ \\
\hline & Eat spicy foods to stimulate the salivary glands & $26(6)$ \\
\hline & Use liquid to soften foods & $222(60)$ \\
\hline \multirow{4}{*}{$\begin{array}{l}\text { Q19. What can help a patient who is experiencing mouth } \\
\text { pain during/after radiotherapy? "Mark all that apply" }\end{array}$} & Mouthrinse containing alcohol & $75(20.3)$ \\
\hline & Lip balm & $134(36.2)$ \\
\hline & Topical anesthetics & 295 (79.7) \\
\hline & Chewing ice & $95(25.7)$ \\
\hline \multirow{4}{*}{$\begin{array}{l}\text { Q20. When should daily oral hygiene be suspended? } \\
\text { "Mark all that apply" }\end{array}$} & When the patient experiences mouth pain & $57(15.4)$ \\
\hline & When the patient has difficulty swallowing & $42(11.4)$ \\
\hline & When the patient has an oral infection & $66(17.5)$ \\
\hline & Never & $270(73)$ \\
\hline
\end{tabular}

*, Yes responses are presented for each choice regarding "Mark all that apply" questions; Bolded responses represent the correct/possible answers.

(Table 2) presents the responses of the whole sample to the included knowledge questions. Worthy to mention that (Table 2) presents the whole questions' stems with their choices and can be referred to while reading the subsequent tables. The bold responses indicate correct/ possible answers. The percentages of the correct answers range from as low as 26.2 for "The oral cavity is often subject to complications from radiotherapy because: all foods aggravate weakened tissues" to as high as $97 \%$ for "As a dentist, do you think that there is any necessity for oral/dental assessment before radiotherapy for head and neck cancer patients?" The per cent of correct answers by the respondents in 18 questions out of 31 was above $75 \%$.

Gender-wise comparisons showed higher knowledge in favor of females (Table 3). For example, higher proportion of females than males marked dental caries (83.2\% vs. 66.4$)$ and osteoradionecrosis $(92.9 \%$ vs. $84.8 \%$ ) as potential complications of head and neck radiotherapy that must be discussed with the patients ahead of the commencing the treatment. Meanwhile lower proportion of females than males (12.4\% vs. $23.3 \%)$ marked "The tissue in the oral cavity thickens" as a cause of complications of head and neck radiotherapy. One exception was that more females than males $(85 \%$ vs.

Table 3. Responses* by Gender (Only Significant Associations are Presented)

\begin{tabular}{|c|c|c|c|c|}
\hline \multirow[t]{2}{*}{ Questions $^{\dagger}$} & \multirow[t]{2}{*}{ Choices } & \multicolumn{2}{|c|}{ Gender } & \multirow[t]{2}{*}{ P value } \\
\hline & & Males n (\%) & Females n $(\%)$ & \\
\hline \multirow[t]{4}{*}{ Q9 } & Extraction of teeth with poor prognosis & $215(83.3)$ & $108(95.6)$ & 0.001 \\
\hline & Loss or change of taste sensation & $201(78.2)$ & $101(89.4)$ & 0.013 \\
\hline & Dental caries & $171(66.5)$ & $94(83.2)$ & 0.001 \\
\hline & Osteoradionecrosis & $218(84.8)$ & $105(92.9)$ & 0.041 \\
\hline \multirow[t]{2}{*}{ Q10 } & Fluoride toothpaste & $203(79)$ & $101(89.4)$ & 0.018 \\
\hline & Alcohol containing mouthwash & $193(75.1)$ & $96(85)$ & 0.04 \\
\hline \multirow[t]{4}{*}{ Q13 } & Every 3-4 months & $213(82.9)$ & $83(73.5)$ & 0.028 \\
\hline & Once a year & $10(3.9)$ & $2(1.8)$ & \\
\hline & Twice a year & $28(10.9)$ & $25(22.1)$ & \\
\hline & Only as needed & $6(2.3)$ & $3(2.7)$ & \\
\hline \multirow[t]{3}{*}{ Q15 } & All foods aggravate weakened tissues & $78(30.4)$ & $19(16.8)$ & 0.007 \\
\hline & The tissue in the oral cavity thickens & $60(23.3)$ & $14(12.4)$ & 0.016 \\
\hline & Soft tissues in the mouth become easily damaged and infected & $231(89.9)$ & $111(98.2)$ & 0.005 \\
\hline \multirow[t]{2}{*}{ Q16 } & $\begin{array}{l}\text { Oral mucositis can increase the risk of oral pain and systemic } \\
\text { infection }\end{array}$ & $201(78.2)$ & $99(87.6)$ & 0.043 \\
\hline & $\begin{array}{l}\text { Oral complications may lead to lowering the dosages and possibly } \\
\text { discontinuing cancer treatment }\end{array}$ & $82(31.9)$ & $24(21.2)$ & 0.045 \\
\hline
\end{tabular}

\footnotetext{
*, Yes responses are presented for each choice regarding "Mark all that apply" questions; $\uparrow$, The corresponding questions are presented in Table 2.
}

${ }^{\mathrm{F}}$, Chi square/Fisher exact tests as appropriate. 
DOI:10.31557/APJCP.2021.22.7.2033

Oral and Dental Assessment of Complications of Radiotherapy for Head and Neck Cancer

Table 4. Responses* by Specialty (Only Significant Associations are Ppresented)

\begin{tabular}{|c|c|c|c|c|c|c|c|c|}
\hline \multirow[t]{2}{*}{ Questions $^{\dagger}$} & \multirow[t]{2}{*}{ Choices } & \multicolumn{6}{|c|}{ Specialty } & \multirow[t]{2}{*}{ P value $^{\mathrm{F}}$} \\
\hline & & GD & OSMP & Endo & Perio & Pros & Others & \\
\hline \multirow[t]{4}{*}{ Q8 } & $\begin{array}{l}\text { Appropriate radiographs such as full mouth } \\
\mathrm{x} \text {-ray and panorama }\end{array}$ & $108(75)$ & $49(86)$ & $30(88.2)$ & $29(90.6)$ & $16(100)$ & $63(72.4)$ & 0.014 \\
\hline & $\begin{array}{l}\text { Extraction of deeply impacted teeth without } \\
\text { pathology }\end{array}$ & $40(27.8)$ & $27(47.4)$ & $7(20.6)$ & $13(40.6)$ & $4(25)$ & $24(27.6)$ & 0.038 \\
\hline & Fluoride application & $60(41.7)$ & $40(70.2)$ & $18(52.9)$ & $15(46.9)$ & $13(81.3)$ & $54(62.1)$ & $<0.001$ \\
\hline & Extraction of teeth with poor prognosis & $116(80.6)$ & $56(98.2)$ & $26(76.5)$ & $31(96.9)$ & $15(93.8)$ & $78(89.7)$ & 0.002 \\
\hline \multirow[t]{6}{*}{ Q9 } & Oral Mucositis & $94(65.3)$ & $52(91.2)$ & $26(76.5)$ & $28(87.5)$ & $16(100)$ & $63(72.4)$ & $<0.001$ \\
\hline & Loss or change of taste sensation & $116(80.6)$ & $51(89.5)$ & $22(64.6)$ & $28(87.5)$ & $16(100)$ & $69(79.3)$ & 0.018 \\
\hline & Oral candidiasis & $83(57.6)$ & $51(89.5)$ & $27(79.4)$ & $26(81.3)$ & $13(81.3)$ & $65(74.7)$ & $<0.001$ \\
\hline & Difficulty in mouth opening & $59(41)$ & $49(86)$ & $11(32.4)$ & $20(62.5)$ & $12(75)$ & $44(50.6)$ & $<0.001$ \\
\hline & Dental caries & $82(56.9)$ & $47(82.5)$ & $28(82.4)$ & $25(78.1)$ & $15(93.8)$ & $68(78.2)$ & $<0.001$ \\
\hline & Osteoradionecrosis & $82(56.9)$ & $47(82.5)$ & $28(82.4)$ & $28(78.1)$ & $15(93.8)$ & $78(89.7)$ & $<0.001$ \\
\hline \multirow[t]{3}{*}{ Q10 } & Alcohol-free antiseptics & $75(52.1)$ & $30(52.6)$ & $19(55.9)$ & $22(68.8)$ & $13(81.3)$ & $61(70.1)$ & 0.023 \\
\hline & Hard toothbrush & $10(6.9)$ & $1(1.8)$ & $6(17.6)$ & $0(0)$ & $0(0)$ & $5(5.7)$ & 0.022 \\
\hline & Fluoride toothpaste & $106(73.6)$ & $55(96.5)$ & $28(82.4)$ & $26(81.3)$ & $15(93.8)$ & $74(85.1)$ & 0.004 \\
\hline \multirow[t]{3}{*}{ Q12 } & Yes & $110(76.4)$ & $52(91.2)$ & $32(94.1)$ & $32(100)$ & $14(87.5)$ & $72(82.8)$ & 0.004 \\
\hline & No & $8(5.6)$ & $4(7)$ & $0(0)$ & $0(0)$ & $2(12.5)$ & $4(4.6)$ & \\
\hline & I don't know & $26(18.1)$ & $1(1.8)$ & $2(5.9)$ & $0(0)$ & $0(0)$ & $11(12.6)$ & \\
\hline \multirow[t]{2}{*}{ Q14 } & Refer to a dental specialist & $115(79.9)$ & $51(91.2)$ & $33(97.1)$ & $30(93.8)$ & $16(100)$ & $73(83.9)$ & 0.016 \\
\hline & Refer to otolaryngologist & $51(35.4)$ & $11(19.3)$ & $3(8.8)$ & $9(28.1)$ & $2(12.5)$ & $15(17.2)$ & 0.002 \\
\hline Q15 & The tissue in the oral cavity thickens & $42(29.2)$ & $11(19.3)$ & $2(5.9)$ & $5(15.6)$ & $6(37.5)$ & $8(9.2)$ & 0.001 \\
\hline Q16 & $\begin{array}{l}\text { Oral complications may lead to lowering } \\
\text { the dosages and possibly discontinuing } \\
\text { cancer treatment }\end{array}$ & $36(25)$ & $21(36.5)$ & $6(17.6)$ & $12(37.5)$ & $9(56.3)$ & $22(25.3)$ & 0.028 \\
\hline Q17 & There is a change in the flow rate for saliva & $140(97.2)$ & $52(91.2)$ & $32(94.1)$ & $31(96.9)$ & $13(81.3)$ & $76(87.4)$ & 0.029 \\
\hline Q18 & $\begin{array}{l}\text { Eat spicy foods to stimulate the salivary } \\
\text { glands }\end{array}$ & $9(6.3)$ & $3(5.3)$ & $0(0)$ & $0(0)$ & $2(12.5)$ & $12(13.8)$ & 0.033 \\
\hline Q19 & Topical anesthetics & $124(86.1)$ & $46(80.7)$ & $20(58.5)$ & $28(87.5)$ & $11(68.8)$ & $66(75.9)$ & 0.007 \\
\hline
\end{tabular}

", Yes responses are presented for each choice regarding "Mark all that apply" questions; ${ }^{\dagger}$, The corresponding questions are presented in Table 2.

${ }^{\mathrm{F}}$, Chi square/Fisher exact tests as appropriate.

75.1\%) thought that "Alcohol containing mouthwash" should be recommended by the dentists before head and neck radiotherapy.

(Table 4) presents the distribution of responses by dental specialty. Obviously, specialty variable showed the vast majority of differences. The general dentists showed lower knowledge compared to the other specialties. Surprisingly, oral surgery/medicine/ pathology, prosthodontists and periodontists showed higher knowledge in most of the included questions. For example, $36.5 \%, 37.5 \%$ and $56 \%$ of oral surgery/ medicine/pathology, prosthodontists and periodontists, respectively, reported that oral complications may lead to lowering the dosages and possibly discontinuing cancer treatment in comparison to $25 \%, 17 \%$, and $25.3 \%$ of general dentists, endodontists and other specialties.

The responses based on work sector are presented in (Table 5). Dentists or dental specialists working in universities or public hospitals revealed higher knowledge compared to those working in the private clinics and health care centers. For example, $89.9 \%$ and $87.4 \%$ of those working in public hospitals and universities, respectively, reported that patients undergoing cancer treatment may experience alterations in taste perception compared to $69.2 \%$ and $77.8 \%$ of those working in health

care center and private clinic/center, respectively.

Few differences were reported based on the year of experience as shown in (Table 6), with no constant association with specific duration of dental profession, although those who worked less than 5 years showed somewhat lower knowledge. For example, $23 \%$ of whose experience was less than 5 years reported that the tissue in the oral cavity thickens with radiotherapy in comparison to $21.7 \%$ and $9 \%$ of whose experience was between 5-10 years and more than 10 years, respectively.

With regard to the region of work, dentist and dental specialists working in the central and western regions showed the highest levels of knowledge in most of the included questions, while those working in the northern and to less extent those working in the eastern regions revealed the lowest levels of knowledge (Table 7). For example, $94.8 \%$ and $96.8 \%$ of those working in the central and western regions, respectively, suggested extraction of teeth with poor prognosis ahead of radiotherapy in comparison to $79.2 \%, 80.8 \%$ and $80.8 \%$ of those working in the eastern, northern and southern regions, respectively, who reported the same. 
Table 5. Responses* by Work Sector (Only Significant Associations are Presented)

\begin{tabular}{|c|c|c|c|c|c|c|}
\hline \multirow[t]{2}{*}{ Questions $^{\dagger}$} & \multirow[t]{2}{*}{ Choices } & \multicolumn{4}{|c|}{ Specialty } & \multirow[t]{2}{*}{$\mathrm{P}_{\text {value }}^{\mathrm{F}}$} \\
\hline & & Health care center & Private clinic/center & Public hospital & University & \\
\hline \multirow[t]{3}{*}{ Q6 } & Yes & $36(92.3)$ & $17(94.4)$ & $78(98.7)$ & $228(97)$ & 0.047 \\
\hline & No & $0(0)$ & $1(5.6)$ & $0(0)$ & $1(0.4)$ & \\
\hline & I don't know & $3(7.7)$ & $0(0)$ & $1(1.3)$ & $5(2.1)$ & \\
\hline \multirow[t]{4}{*}{ Q7 } & $\begin{array}{l}\text { After a cancer diagnosis and before } \\
\text { radiotherapy }\end{array}$ & $36(92.3)$ & $13(72.2)$ & $75(94.9)$ & $218(93.2)$ & 0.004 \\
\hline & After finishing radiotherapy & $1(2.9)$ & $4(22.2)$ & $3(3.8)$ & $6(2.6)$ & \\
\hline & During radiotherapy & $2(5.1)$ & $1(5.6)$ & $0(0)$ & $2(0.9)$ & \\
\hline & Only as needed & $0(0)$ & $0(0)$ & $1(1.3)$ & $8(3.4)$ & \\
\hline Q8 & Fluoride application & $12(30.8)$ & $8(44.4)$ & $45(57)$ & $135(57.7)$ & 0.013 \\
\hline \multirow[t]{3}{*}{ Q9 } & Oral Mucositis & $23(59)$ & $10(55.6)$ & $62(78.5)$ & $184(78.6)$ & 0.011 \\
\hline & Difficulty in mouth opening & $17(43.6)$ & $8(44.4)$ & $28(35.4)$ & $142(60.7)$ & $<0.001$ \\
\hline & Osteoradionecrosis & $29(74.4)$ & $13(72.2)$ & $72(91.1)$ & $209(89.3)$ & 0.011 \\
\hline Q10 & Hard toothbrush & $5(12.5)$ & $4(22.2)$ & $2(2.5)$ & $11(4.7)$ & 0.005 \\
\hline \multirow[t]{3}{*}{ Q12 } & Yes & $28(71.8)$ & $14(77.8)$ & $69(87.3)$ & $201(85.9)$ & 0.011 \\
\hline & No & $0(0)$ & $1(5.6)$ & $4(5.1)$ & $13(5.6)$ & \\
\hline & I don't know & $11(28.2)$ & $3(16.7)$ & $6(7.6)$ & $20(8.5)$ & \\
\hline \multirow[t]{2}{*}{ Q14 } & Refer to a dental specialist & $31(79.5)$ & $11(61.1)$ & $15(81)$ & $213(91)$ & 0.001 \\
\hline & No need for any treatment & $0(0)$ & $4(22.2)$ & $0(0)$ & $3(1.3)$ & $<0.001$ \\
\hline Q15 & The tissue in the oral cavity thickens & $12(30.8)$ & $7(38.9)$ & $10(12.7)$ & $45(19.2)$ & 0.022 \\
\hline \multirow[t]{2}{*}{ Q16 } & $\begin{array}{l}\text { High dosages of radiation cannot } \\
\text { affect dental or skeletal development } \\
\text { in children }\end{array}$ & $1(2.6)$ & $3(16.7)$ & $1(1.3)$ & $16(6.3)$ & 0.044 \\
\hline & $\begin{array}{l}\text { Patients undergoing cancer treatment } \\
\text { may experience alterations in taste } \\
\text { perception }\end{array}$ & $27(69.2)$ & $14(77.8)$ & $71(89.9)$ & $204(87.4)$ & 0.012 \\
\hline
\end{tabular}

", Yes responses are presented for each choice regarding "Mark all that apply" questions; ${ }^{\dagger}$, The corresponding questions are presented in Table 2.

${ }^{\mp}$, Chi square/Fisher exact tests as appropriate.

\section{Discussion}

Oral and paraoral complications of radiotherapy to the head and neck area are well-documented, and so are the proposed guidelines for management that are continually updated (Kumar et al., 2018; Nekhlyudov et al., 2018; Nekhlyudov et al., 2017; Samim et al., 2016; Beech et al., 2014; Plemons et al., 2013; Hancock et al., 2003). However, little is known about the extent to which dental practitioners are aware and knowledgeable about these complications and their proper management. Hence, this study sought to assess the knowledge and practice of dental practitioners working in Saudi Arabia in this context.

The results revealed astonishing knowledge in terms of the need for, and the proper timing of, dental/oral assessment for the cancer patients who are to undergo radiotherapy to the head and neck area ( $97 \%$ and $92 \%$, respectively). Contrastingly, the results unveiled highly variable knowledge levels when it comes to the individual radiotherapy complications and their individual management procedures; the correct answers ranged from as low as $26 \%$ to as high as $93 \%$. Somewhat similar knowledge levels, or even lower, were reported

Table 6. Responses* by Experience (Only Significant Associations are Presented)

\begin{tabular}{llcccc}
\hline Questions $^{\dagger}$ & Choices & & Experience & & P value $^{\mathrm{F}}$ \\
& & $<5$ years & $5-10$ years & $>10$ years \\
\hline Q8 & Extraction of teeth with poor prognosis & $161(88)$ & $109(90.8)$ & $52(77.6)$ & 0.031 \\
Q9 & Dental caries & $120(65.6)$ & $93(77.5)$ & $52(77.6)$ & 0.038 \\
& Osteoradionecrosis & $163(89.1)$ & $108(90)$ & $52(77.6)$ & 0.032 \\
Q10 & Alcohol containing mouthwash & $37(20.2)$ & $9(7.5)$ & $7(10.4)$ & 0.005 \\
Q15 & The tissue in the oral cavity thickens & $46(25.1)$ & $42(35)$ & $9(13.4)$ & 0.005 \\
& Many patients experience hypersalivation & $20(10.9)$ & $4(3.3)$ & $4(6)$ & 0.046 \\
& The tissue in the oral cavity thickens & $42(23)$ & $26(21.7)$ & $6(9)$ & 0.045 \\
Q19 & Chewing ice & $45(24.6)$ & $39(32.5)$ & $11(16.4)$ & 0.047 \\
\hline
\end{tabular}

", Yes responses are presented for each choice regarding "Mark all that apply" questions. ", The corresponding questions are presented in Table 2. ${ }^{\mathrm{F}}$, Chi square/Fisher exact tests as appropriate. 
DOI: 10.31557/APJCP.2021.22.7.2033

Oral and Dental Assessment of Complications of Radiotherapy for Head and Neck Cancer

Table 7. Responses* by Region of Work (Only Significant Associations are Presented)

\begin{tabular}{|c|c|c|c|c|c|c|c|}
\hline \multirow[t]{2}{*}{ Questions $^{\dagger}$} & \multirow[t]{2}{*}{ Choices } & \multicolumn{5}{|c|}{ Region } & \multirow[t]{2}{*}{$\mathrm{P}$ value ${ }^{\mathrm{T}}$} \\
\hline & & Central & Eastern & Northern & Southern & Western & \\
\hline \multirow[t]{3}{*}{ Q6 } & Yes & $112(97.4)$ & $21(87.5)$ & $45(93.6)$ & $119(99.2)$ & $62(98.4)$ & 0.03 \\
\hline & No & $0(0)$ & $1(4.2)$ & $0(0)$ & $1(0.8)$ & $0(0)$ & \\
\hline & I don't know & $3(2.6)$ & $2(8.3)$ & $3(6.3)$ & $0(0)$ & $1(1.6)$ & \\
\hline \multirow[t]{2}{*}{ Q8 } & Fluoride application & $76(66.1)$ & $14(58.3)$ & $16(33.3)$ & $56(46.7)$ & $38960)$ & 0.001 \\
\hline & Extraction of teeth with poor prognosis & $109(94.8)$ & $19(79.2)$ & $97(80.8)$ & $97(80.8)$ & $61(96.8)$ & $<0.001$ \\
\hline \multirow[t]{5}{*}{ Q9 } & Oral Mucositis & $97(84.3)$ & $13(54.2)$ & $26(54.2)$ & $90(75)$ & $53(84.1)$ & $<0.001$ \\
\hline & Oral candidiasis & $94(81.7)$ & $10(41.7)$ & $30(62.5)$ & $82(68.3)$ & $49(77.8)$ & $<0.001$ \\
\hline & Difficulty in mouth opening & $63(54.8)$ & $13(54.2)$ & $14(29.2)$ & $65(54.2)$ & $40(63.5)$ & 0.007 \\
\hline & Dental caries & $90(78.3)$ & $13(54.2)$ & $27(56 ., 3)$ & $82(68.3)$ & $53(84.1)$ & 0.002 \\
\hline & Osteoradionecrosis & $103(89.6)$ & $21(87.5)$ & $38(79.2)$ & $100(83.3)$ & $61(96.8)$ & 0.036 \\
\hline \multirow[t]{4}{*}{ Q10 } & Alcohol-free antiseptics & $62(53.9)$ & $7(29.2)$ & $26(54.2)$ & $83(69.2)$ & $42(66.7)$ & 0.002 \\
\hline & Hard toothbrush & $2(1.7)$ & $1(4.2)$ & $6(12.5)$ & $12(10)$ & $1(1.6)$ & 0.012 \\
\hline & Fluoride toothpaste & $106(92.2)$ & $17(70.8)$ & $33(68.8)$ & $92(76.7)$ & $56(88.9)$ & 0.001 \\
\hline & Salivary substitute & $94(81.7)$ & $17(70.8)$ & $30(62.5)$ & $92(76.7)$ & $56(88.9)$ & 0.012 \\
\hline \multirow[t]{2}{*}{ Q14 } & Refer to otolaryngologist & $19(16.5)$ & $7(29.2)$ & $17(37.5)$ & $36(30)$ & $11(17.5)$ & 0.015 \\
\hline & No need for any treatment & $1(0.9)$ & $0(0)$ & $4(8.3)$ & $2(1.7)$ & $0(0)$ & 0.017 \\
\hline \multirow[t]{4}{*}{ Q15 } & All foods aggravate weakened tissues & $19(16.5)$ & $5(20.8)$ & $12(25)$ & $43(35.8)$ & $18(28.6)$ & 0.018 \\
\hline & $\begin{array}{l}\text { Many patients experience } \\
\text { hypersalivation }\end{array}$ & $1(0.9)$ & $2(8.3)$ & $9(18.8)$ & $11(9.2)$ & $5(7.9)$ & 0.003 \\
\hline & The tissue in the oral cavity thickens & $13(11.3)$ & $4(16.7)$ & $15(31.3)$ & $26(21.7)$ & $16(25.4)$ & 0.029 \\
\hline & $\begin{array}{l}\text { Soft tissues in the mouth become } \\
\text { easily damaged and infected }\end{array}$ & $114(99.1)$ & $20(83.3)$ & $42(87.5)$ & $104(86.7)$ & $62(98.2)$ & 0.001 \\
\hline
\end{tabular}

*, Yes responses are presented for each choice regarding "Mark all that apply" questions. ', The corresponding questions are presented in Table 2.

${ }^{\mp}$, Chi square/Fisher exact tests as appropriate.

in a similar study targeted Turkish dentists (Guneri et al., 2008). The picture was worse concerning Turkish senior dental students; their knowledge levels ranged from 5.2 to $98.7 \%$ (Alopz et al., 2013). Variable knowledge was reported too in the approach of practitioners in restorative dentistry (Dewan et al., 2014) and oncology (Mainali et al., 2011) in context of radiotherapy for head and neck cancer patients. It seems that this issue is neither covered properly in the educating institutes nor dealt seriously by the dental/oncologic relevant authorities. Indeed, a recent study concluded that only $48.6 \%$ New Zealand and $2.5 \%$ Malaysian dentists followed formal guidelines or protocols for dental assessment of head and neck cancer patients, and hence recommended developing/[activating the current] clinical guidelines and generalizing them to all relevant practitioners in order to support effective medical/dental treatment and management strategies for this vulnerable population (Suhaimi, 2017).

It was surprising that $31 \%$ of the respondents reported that oral/dental assessment and management should include "Extraction of deeply impacted teeth without pathology." It is an axiom that the intervention should not be performed on teeth that don't represent sources of infection irrespective of the systemic conditions the patients have, or the treatment modalities planned. Basically, one of the guidelines for this class of patients is that "All healthy teeth as well as deeply impacted teeth without pathology are left in situ" (Beech et al., 2014).
It was also surprising that $81 \%$ that "oral mucositis can increase the risk of oral pain and systemic infection." Although oral mucositis represents a real problem associated with poor oral functions including difficulties in eating and swallowing which ultimately lead to poor quality of life (Martins et al., 2020; Morais et al., 2020), it is not linked directly with systemic infections. One of the low-scored knowledge items was that $71 \%$ of the respondents didn't though that "oral complications may lead to lowering the dosages and possibly discontinuing cancer treatment". In fact, the more sever the oral complications the more urgent the need to suspend the radiotherapy (Morais et al., 2020; Agarwal et al., 2012).

More than $14 \%$ of the respondents reported that "alcohol-based mouthwashes" can be recommended for head and neck cancer patients before radiotherapy and $20 \%$ reported that these mouthwashes can be prescribed to control pain during or after radiotherapy. One of the main guidelines in management of the head and neck patients who are either to undergo or currently under radiotherapy, however, is to use alcohol-free mouthwashes and/or topical preparations (Kumar et al., 2018; Nekhlyudov et al., 2018; Nekhlyudov et al., 2017; Suhaimi, 2017; Samim et al., 2016).

Although no differences by gender, age, experience and specialty were reported in Güneri study in Turkey, our study concluded contradicting results; female dental practitioners revealed better knowledge in many of the 
questionnaire items. In context of gender difference in knowledge on oral cancer, many previous studies revealed highly variable results (Rahman et al., 2013; Chowdhury et al., 2010; Leao et al., 2005; Powe and Finnie, 2004). It is difficult to justify why females revealed better knowledge, but this can be partially ascribed to being more careful and they study harder during their graduate and postgraduate studies.

It is a foregone conclusion that with higher level of educations (specialties) the knowledge is higher. In our study, the general dental practitioners scored the lowest knowledge compared to the other specialties. Although, it was expected that oral/maxillofacial surgeons/pathologist/ medicine specialists would have had higher knowledge compared to others, the prosthodontists were the best in many key items. Again, this is difficult to explain at least in light of the cross-sectional design of our study. In a recent study on prosthodontists in Saudi Arabia, they reflected good knowledge about oral cancer (Alqutaibi et al., 2020).

In our study, higher knowledge was obtained by those working in public sectors or universities compared to the private sector, and in the central and western regions compared to other regions of the Saudi Arabia. Concerning the working sector, this is simply due to the continuous educating programs conducted in the public sectors and universities, and the shorter working hours there in contrast to the private sector. Regarding the region of work, it is well known that the central and western regions of the Saudi Arabia are well developed and have had long time since the health infrastructures were established there compared to the other regions which are less developed. Consequently, for the health practitioners to persist in the central and western regions areas, they have to be highly competitive.

Each study has its own drawbacks and positives. Among the drawbacks is being of a cross-sectional, questionnairebased design, and it is well-known the inherent weakness such studies had in terms of the pyramid of evidence. It is highly encouraged to conduct a prospective study in which the knowledge is measure pre- and post-training workshop on the topic. Another drawback is the small sample size relative to the huge population framework (dental practitioners in Saudi Arabia), though we tried our best to increase the number through many reminders using the different social media and emails. Another limitation is related to the multiple comparisons conducted which inflate the possibility of false positive responses due to the multiple comparison bias, although this is an inherited feature of the questionnaire-based studies owing to the numerous items (outcomes) and numerous independent explanatory variables included. Nevertheless, the current study is exploratory (hypotheses-generating); that is to say any positive association (false or true) must be dealt as a hypothesis for further research, not to build on it a practice or policy. Accordingly, interpretation of the results must be cautious, away from being over-extrapolated. However, and up to our knowledge, this study is the first that assessed the knowledge of dental practitioners in Saudi Arabia complications and management of radiotherapy to the head and neck area.

To sum up, our results show highly variable knowledge of dental practitioners on complications and management of radiotherapy to the head and neck area; that knowledge seems to fluctuate considerably with gender, experience, work sector, working region and specialty. The relevant authorities have the responsibility of provisioning and disseminating guidelines for proper approach in management of patients who are to undergo radiotherapy owing to head and neck cancer. Further, well-designed, large-scaled studies in this context are highly encouraged.

\section{Author Contribution Statement}

The authors confirm contribution to the paper as follows: Study conception and design: Ahmed Shaher Alqahtani and Esam Halboub; data collection: Yaser Alhazmi, Yousef Alshamrani; analysis and interpretation of results: Esam Halboub; draft manuscript preparation: Ahmed shaher Alqahtani and Esam Halboub. All authors reviewed the results and approved the final version of the manuscript.

\section{Acknowledgments}

\section{None.}

\section{References}

Agarwal P, Upadhyay R, Agarwal A (2012). Radiotherapy complications and their possible management in the head and neck region. Indian J Dent Res, 23, 843.

Al-Hebshi NN, Skaug N (2005). Khat (Catha edulis)-an updated review. Addict Biol, 10, 299-07.

Alpöz E, Güneri P, Epstein J, et al (2013). Dental students' knowledge of characteristics and management of oral complications of cancer therapy. Support Care Cancer, 21, 2793-98.

Alqutaibi AY, Borzangy S, Al-Maweri SA, Aboalrejal A (2020). Early detection of oral cancer and potentially malignant disorders: Experiences, practices, and beliefs of prosthodontists practicing in Saudi Arabia. J Prosthet Dent, S0022-3913, 30434-0 [Online ahead of print].

Amin MB, Greene FL, Edge SB, et al (2017). The Eighth Edition AJCC Cancer Staging Manual: Continuing to build a bridge from a population-based to a more "personalized" approach to cancer staging. CA CA Cancer J Clin, 67, 93-99.

Bacher H, Schweyen R, Kuhnt T, Leplow B, Hey J (2020). Use of a patient information leaflet on oro-dental care during radiotherapy. Patient Prefer Adherence, 14, 1751-59.

Beech N, Robinson S, Porceddu S, Batstone M (2014). Dental management of patients irradiated for head and neck cancer. Aust Dent J, 59, 20-8.

Boñar-Álvarez P, Padin-Iruegas E, Chamorro-Petronacci C, et al (2020). Assessment of saliva and oral candidiasis levels 12, 24 and 36 months after radiotherapy in patients with head and neck cancer. J Stomatol Oral Maxillofac Surg, S24687855, 30228-7. [Online ahead of print].

Brook I (2020). Late side effects of radiation treatment for head and neck cancer. Radiat Oncol J, 38, 84-92.

Cho H, Kumar N (2019). Dental management of a patient with head and neck cancer: a case report. Br Dent J, 227, 25-29.

Chowdhury MT, Pau A, Croucher R (2010). Bangladeshi dental students' knowledge, attitudes and behaviour regarding tobacco control and oral cancer. JCancer Educ, 25, 391-95.

Colloc T, Brown T, Keys W (2020). Role of the consultant 
in restorative dentistry in managing head and neck cancer patients undergoing radiotherapy: a novel intraoral shield appliance design. $B r$ Dent $J, 229,655-60$.

Dewan K, Kelly RD, Bardsley P (2014). A national survey of consultants, specialists and specialist registrars in restorative dentistry for the assessment and treatment planning of oral cancer patients. Br Dent J, 216, E27.

Güneri P, Cankaya H, Kaya A, Boyacioğlu H (2008). Turkish dentists' knowledge of head and neck cancer therapy-related complications: implications for the future. Eur $J$ Cancer Care, 17, 84-92.

Hancock PJ, Epstein JB, Sadler GR (2003). Oral and dental management related to radiation therapy for head and neck cancer. J Can Dent Assoc, 69, 585-90.

Kumar N, Brooke A, Burke M, et al (2018). The Oral Management of Oncology Patients Requiring Radiotherapy, Chemotherapy and / or Bone Marrow Transplantation Clinical Guidelines. 1997 Updated 2018, The Royal College of Surgeons of England: England.

Jasmer KJ, Gilman KE, Muñoz Forti K, Weisman GA, Limesand KH (2020). Radiation-induced salivary gland dysfunction: mechanisms, therapeutics and future directions. J Clin Med, 9, 4095 .

Leão JC, Góes P, Sobrinho CB, Porter S (2005). Knowledge and clinical expertise regarding oral cancer among Brazilian dentists. Int J Oral Maxillofac Surg, 34, 436-39.

Mainali A, Sumanth KN, Ongole R, Denny C (2011). Dental consultation in patients planned for/undergoing/post radiation therapy for head and neck cancers: a questionnairebased survey. Indian J Dent Res, 22, 669-72.

Martinez AC, Silva I, Berti Couto SA, et al (2020). Late oral complications caused by head and neck radiotherapy: clinical and laboratory study. J Oral Maxillofac Res, 11, e3.

Martins AFL, Morais MO, de Sousa-Neto SS, et al (2021). Photobiomodulation reduces the impact of radiotherapy on oral health-related quality of life due to mucositis-related symptoms in head and neck cancer patients. Lasers Med Sci, 36, 903-12.

McCaul LK (2012). Oral and dental management for head and neck cancer patients treated by chemotherapy and radiotherapy. Dent Update, 39, 135-40.

Moore C, McLister C, O’Neill C, Donnelly M, McKenna G (2020). Pre-radiotherapy dental extractions in patients with head and neck cancer: a Delphi study. J Dent, 97, 103350.

Morais MO, Martins A, de Jesus A, et al (2020). A prospective study on oral adverse effects in head and neck cancer patients submitted to a preventive oral care protocol. Support Care Cancer, 28, 4263-73.

Nekhlyudov L, Lacchetti C, Siu LL (2018). Head and neck cancer survivorship care guideline: American Society of Clinical Oncology Clinical Practice Guideline Endorsement Summary. J Oncol Pract, 14, 167-71.

Nekhlyudov L, Lacchetti C, Davis NB, et al (2017). Head and neck cancer survivorship care guideline: American Society of Clinical Oncology Clinical Practice Guideline Endorsement of the American Cancer Society Guideline. $J$ Clin Oncol, 35, 1606-21.

Patil S, Alamir A, Arakeri G, et al (2019). The relationship of shammah (Arabian snuff) chewing to the risk of oral cancer and oral potentially malignant disorders. J Oral Pathol Med, 48, 425-32.

Plemons JM, Rankin KV, Benton E (2013). Oral health care in cancer patients: you can make a difference!. Tex Dent $J$, 130, 682-90.

Powe BD, Finnie R (2004). Knowledge of oral cancer risk factors among african americans: do nurses have a role?. Oncol Nurs Forum, 31, 785-91.
Quadri MFA, Tadakamadla SK, John T (2019). Smokeless tobacco and oral cancer in the Middle East and North Africa: A systematic review and meta-analysis. Tob Induc Dis, 17, 56.

Quadri MFA, Alharbi F, Bajonaid AM, et al (2015). Oral squamous cell carcinoma and associated risk factors in Jazan, Saudi Arabia: a hospital based case control study. Asian Pac J Cancer Prev, 16, 4335-38.

Rahman B, Hawas N, Rahman MM, Rabah AF, Al Kawas S (2013). Assessing dental students' knowledge of oral cancer in the United Arab Emirates. Int Dent J, 63, 80-4.

Samim F, Epstein JB, Zumsteg ZS, Ho AS, Barasch A (2016). Oral and dental health in head and neck cancer survivors. Cancers Head Neck, 1, 14.

Shih A, Miaskowski C, Dodd MJ, Stotts NA, MacPhail L (2003). Mechanisms for radiation-induced oral mucositis and the consequences. Cancer Nurs, 26, 222-9.

Suhaimi AA (2017). Awareness of pre-radiation dental assessment of head and neck cancer patients among dentists in Malaysia and New Zealand, in Special Needs Dentistry. University of Otago: Dunedin, New Zealand.

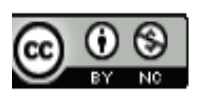

This work is licensed under a Creative Commons AttributionNon Commercial 4.0 International License. 